\title{
Comportamiento informacional en una comunidad científica formada a partir de la implementación de proyectos colaborativos institucionales
}

\begin{abstract}
Dámaris Valero Rivero
\end{abstract}
Profesora Auxiliar en el Departamento de Ciencias de la Información de la Universidad de Sancti Spíritus "José Martí Pérez" (Cuba)

María Pinto Molina

Catedrática del Departamento de Biblioteconomía y Documentación Universidad de Granada (España)

Gloria Ponjuán Dante

Profesora Titular en el Departamento de Ciencias de la Información de la Universidad de La Habana (Cuba)

http://dx.doi.org/10.1590/1981-5344/2032

La investigación que se presenta forma parte de un estudio realizado a un grupo de profesionales pertenecientes a las ciencias puras, naturales, exactas $y$ aplicadas que conforman una comunidad científica formada a partir de un proyecto colaborativo institucional, liderado por el Instituto de Medicina Tropical "Pedro Kouri", en la provincia de Sancti Spíritus. El objetivo de este estudio se encauzó en determinar las características $y$ el comportamiento informacional de los especialistas que conformaban la comunidad científica investigada; para ello el basamento fundamental de la investigación estuvo dado en indagar cuáles eran las fuentes y recursos informativos más utilizados; así como la relación existente entre el grado de estudio, edad, tipo y etapa de investigación con el recurso de información y fuente informativa que utilizan los investigadores de esta comunidad científica cuando precisan satisfacer sus constantes necesidades informativas. Fue aplicado un cuestionario a los miembros del grupo y los resultados obtenidos fueron analizados de forma descriptiva, empleándose pruebas estadísticas no paramétricas para comprobar la correlación existente entre las variables 
seleccionadas en el estudio. Los resultados se compararon con investigaciones similares realizadas en países de Iberoamérica, fundamentalmente con España y México, demostrando la existencia de coincidencias o puntos de contacto, tales como: el acceso a los paper como primera opción para acceder a los resultados publicados de primera mano, el uso de las publicaciones periódicas, la biblioteca como el recurso de información más utilizado y un elevado uso del texto electrónico debido al creciente acceso a las tecnologías de información.

Palabras Claves: comportamiento informacional; comportamiento informativo; comunidades científicas; necesidades de información; proyectos colaborativos.

\section{Comportamento informacional em uma comunidade científica formada a partir da implementação de projetos colaborativos institucionais}

A presente investigação faz parte de um estudo realizado com um grupo de profissionais pertencentes às ciências naturais, exatas e aplicadas, os quais formam uma comunidade científica criada a partir de um projeto colaborativo institucional liderado pelo Instituto de Medicina Tropical "Pedro Kourí", na província de Sancti Spíritus/Cuba. O objetivo do estudo esteve direcionado à determinação das características e comportamento informacional dos especialistas da comunidade científica pesquisada, visando conhecer quais as fontes e os recursos informativos mais utilizados, bem como a relação existente entre nível de estudo, idade, tipo e etapa da investigação, com o recurso informativo e a fonte que utilizam os pesquisadores da comunidade científica, quando precisam satisfazer as constantes necessidades de informação. Foi aplicado um questionário aos membros do grupo, cujos resultados foram analisados de forma descritiva, utilizando provas estatísticas não paramétricas com o intuito de comprovar a correlação existente entre as variáveis selecionadas no 
estudo. Estes resultados foram comparados com estudos similares realizados em países Iberoamericanos, fundamentalmente na Espanha e no México, apresentando coincidências ou pontos de contato, tais como: o acesso aos papers como primeira opção para verificar aos resultados publicados de primeira mão; o uso das publicações periódicas; a biblioteca como principal recurso de informação, e uma ampla utilização do texto eletrônico devido à massificação das tecnologías da informação.

Palavras-chave: comportamento informacional; comportamento informativo; comunidade científica; projetos colaborativos.

\section{Informational behavior in a scientific community formed from institutional collaborative project implementation}

The research is part of a study carried out to a group of professionals belonging to the scientific, natural, pure, exact and applied sciences which form a scientific community formed from an institutional collaborative project, led by the Tropical Medical Institute "Pedro Kouri" in Sancti Spiritus province. This study is aimed to determine the characteristics and researchers information behavior that make up this studied scientific community. The research was based on inquiring what were the most used sources and information resources as well as the relationship between the degree of study, age, type and stage of research on the type of information resource and source of information they use when they need to meet their information needs. A questionnaire was applied to all members of the group and the results were analyzed descriptively, using nonparametric statistical tests in order to check the correlation between the selected variables. These results were compared with similar studies in Latin American countries, primarily Spain and Mexico, presenting, some overlap or touch points, such as: the use of periodicals and access to the papers as a preferred option to access the published results firsthand, the library and the most used source of information and increased use of electronic text due to increased access to information technologies. 
Keywords: informational behaviour; informative behaviour; scientific communities; needs of information; collaborative projects.

Recebido em 15.03.2014 Aceito em 29.09.2014

\section{Introducción}

En la actualidad las comunidades científicas de primer orden, reconocen el valor de la información y la exigen como un requisito fundamental para realizar investigaciones 0 presentar programas de desarrollo social. Esto se visualiza en los gastos que en cuanto a información y a infraestructura se requiere para su uso. El valor social y económico de la información radica en su reconocimiento individual o colectivo, así como en la necesidad de utilizarla o poseerla. Los conocimientos para el desarrollo de la sociedad se aseguran por medio de la investigación, profesión que para ejercerla se requiere de creatividad, disciplina, dedicación $y$, ante todo de formación. Por tal motivo, las instituciones educativas, académicas y científicas, deben orientarse hacia la formación de investigadores para el avance del trabajo científico, tomando en cuenta que el investigador se forma al participar en el proceso mismo de la investigación científica y para lo cual requiere tener un cúmulo inmenso de información que lo ayude en su práctica diaria y en su devenir profesional.

Es interés de la Ciencia de la Información, específicamente de la Documentación, realizar investigaciones dirigidas a conocer cómo las personas necesitan, buscan, gestionan, difunden y utilizan la información en contextos diferentes (FISHER; ERDELEZ; MCKECHNIE, 2005 citado en GONZÁLEZ-TERUEL, 2010); comienzan así los estudios de Comportamiento Informacional (CI), los cuales en sus inicios eran reconocidos como estudios de necesidades de usuarios de información.

Las primeras investigaciones sobre Comportamiento Informacional (CI), permanecieron recogidas en las ponencias presentadas en 1948, en la celebración de la Royal Society Scientific Information Conference (BAWDEN, 1990; SIATRI, 1999; WILSON, 1981, 1994, 1999 citado en GONZÁLEZ-TERUEL, 2010). Otras investigaciones relacionadas con este tema fueron las realizadas por la American Psychological Association entre 1950 y 1966. Instituciones como: John Hopkins University en Baltimore, Departament of Defense of the USA y el Center for Research on User Studies, fueron pioneras en las investigaciones sobre Comportamiento Informacional (CI) y marcaron las pautas a seguir en este tipo de estudio.

El Comportamiento Informacional (CI), comprende dentro de su campo de estudio a tres elementos básicos: la necesidad de información, el proceso de búsqueda de información y el uso de la información (WILSON, 1999); siendo estos elementos estudiados desde perspectivas diferentes y en su mayoría a través de modelos. Los investigadores más representativos en estos estudios: Belkin (1980), Krikelas (1983) Dervin 
(1983, 1996), Ellis (1989), Kuhlthau (1991), Taylor (1991), Ingwersen (1996), Saracevic (1996), Spink (1997), Niedzwiedzka (2000), y Wilson (1981, 1996, 1997, 1999, 2000).

Actualmente el número de investigaciones publicadas acerca de esta temática es alto en países como: Estados Unidos, Gran Bretaña, España, Alemania, China, Chile, Argentina, Brasil, España y México; aunque es importante enfatizar que la mayoría de estos estudios se orientan fundamentalmente hacia el comportamiento en la búsqueda de información; y un menor número de investigaciones están dirigidas hacia la recuperación y uso de la información. Razón por la cual Calva-González (1999), afirma, que aún hoy día continúan manifestándose en escaso número las investigaciones que aborden el Comportamiento Informacional (CI), desde sus tres dimensiones en comunidades científicas consagradas a las ciencias puras, naturales, exactas y aplicadas.

En Cuba son limitadas las investigaciones que incluyan el análisis del Comportamiento Informacional en sus tres dimensiones y específicamente en comunidades científicas formadas a través de la implementación de un proyecto colaborativo institucional. Por lo que la presente investigación pretende indagar en las características y el Comportamiento Informacional (CI) de la comunidad científica formada a partir de un proyecto liderado por el Instituto de Medicina Tropical "Pedro Kourí" (IPK); y diferentes instituciones de la provincia de Sancti Spíritus entre las que se encuentran:

\section{Centro Provincial de Higiene y Epidemiología (CPHE)}

Centro Provincial de Meteorología de Sancti Spíritus (CMP)

Unidad Provincial de Vigilancia y Lucha Antivectorial de Sancti Spíritus (UPVLA)

Centro Provincial de Promoción y Educación para la Salud de Sancti Spíritus (CPPES)

Universidad de Sancti Spíritus "José Martí Pérez" (UNISS)

Todo esto nos lleva a plantearnos el siguiente:

Objetivo de la investigación:

Determinar las características y el estado del Comportamiento Informacional en la comunidad científica de Sancti Spíritus liderada por el Instituto de Medicina Tropical "Pedro Kourí (IPK)".

Con este estudio se analizó el Comportamiento Informacional (CI) en la comunidad científica formada a partir de un proyecto colaborativo del Instituto de Medicina Tropical "Pedro Kourí" (IPK) e instituciones de la provincia de Sancti Spíritus, que abarcó la caracterización de la comunidad, de los recursos y fuentes de información, las últimas publicaciones realizadas y las vías más utilizadas para comunicar los resultados científicos y el análisis de la relación y/o asociación entre variables mediante la aplicación de pruebas no paramétricas; identificándose de esta manera diferentes patrones de comportamiento informativo relacionados con la búsqueda, recuperación, uso y 
diseminación de la información. La falta de estudios referidos a comunidades científicas de este tipo demostró la necesidad de definir las características propias de la comunidad científica que se investigó con respecto a otras y de establecer generalizaciones a partir de sus comportamientos y la satisfacción de sus necesidades informativas, las cuales pueden ser similares o no a otras comunidades de investigadores.

2 Método

2.1 Diseño

Este estudio se asume desde un enfoque cualitativo, considerado por muchos como un proceso activo, sistemático y riguroso de indagación e interpretación; ya que parte de describir y analizar la naturaleza profunda del fenómeno, orientado a determinar el significado del mismo y la percepción que los sujetos tienen de su realidad. Su empleo, se justifica por la necesidad de descubrir pautas, patrones y regularidades que permiten comprender el sentido, el significado y la construcción personal y social que los sujetos mantienen en los contextos científicos (comunidad científica) en los que funcionan. (BARCA, A., 1996)

El momento actual de la investigación cualitativa se caracteriza por una situación de convergencia de gran diversidad de perspectivas, a pesar de lo cual, en mayor o menor medida, cada una de estas perspectivas comparte una connotación diferenciadora. En el trabajo que se presenta resulta necesario tener en cuenta esta amplitud en la concepción general de la investigación. Se consideran las tres grandes características que la definen: holística, empírica e interpretativa. En este caso el empleo del enfoque cualitativo hace posible que el investigador se centre en el accionar de los miembros de la comunidad científica formada a partir del proyecto "Condicionantes eco-bio-sociales de la proliferación de vectores de importancia médica y veterinaria", visualizando así el Comportamiento Informacional en el grupo de investigadores que interactúa en el mismo.

Se adiciona el enfoque cuantitativo, el cual se utiliza en el estudio para fundamentar las líneas de investigación cualitativa. Los números, son útiles para tener una noción de qué tiene el investigador ante sí, cuando trabaja con un amplio cuerpo de datos, para verificar una sospecha o hipótesis, y para ser lo más honesto posible en el análisis y de esta forma evitar los sesgos. Otros autores afirman que "una vez identificados los elementos, es posible reducirlos a forma cuantificable examinándolos, elaborando listas, codificándolos y asignándoles puntuaciones". (GOETZ, J. P. \& LE COMPTE, M. D., 1998)

El empleo de los métodos del nivel teórico, posibilitan la interpretación conceptual de los datos empíricos encontrados y al utilizarse en la construcción y desarrollo de las teorías, crean las condiciones para ir más allá de las características fenoménicas y superficiales de la realidad, explicar los hechos y profundizar en las relaciones esenciales y las cualidades fundamentales de los procesos no observables directamente. (PÉREZ, G.; GARCÍA. G.; et al, 1996). La utilización de los mismos brinda la posibilidad de analizar e interpretar los hechos teóricos y empíricos de las diferentes fases de la investigación. 
Los métodos empíricos posibilitan revelar las relaciones esenciales y las características fundamentales del objeto de estudio, accesibles a la detección de la percepción, a través de procedimientos prácticos con el objeto y diversos medios de estudio.

El método etnográfico permitió incorporar el análisis de aspectos cualitativos dados por los comportamientos de los individuos, de sus relaciones sociales y de las interacciones con el contexto en que se desarrollan, actualmente se aplica al estudio de las comunidades (urbanas, enfermos mentales, estudiante, académicos, etc.) y en general, a cualquier grupo que se quiera conocer mejor; siendo el caso para esta investigación el uso del mismo para estudiar en profundidad la comunidad científica creada a partir de un proyecto colaborativo institucional. Con él se logra realizar el análisis del modo de vida del grupo de individuos que se han integrado para conformar su propia comunidad científica. Se afirma que el método etnográfico describe las múltiples formas de comportamiento de los seres humanos.

El análisis documental resultó necesario para efectuar el estudio, valoración y generalización de la bibliografía existente sobre el tema objeto de estudio y los paradigmas de modelos de comportamiento informacional existentes. Este método es de gran utilidad en el estudio y valoración de las fuentes bibliográficas localizadas en torno al tema de investigación, así como en la interpretación y análisis de los resultados obtenidos. En la investigación se utilizó documentación importante que aborda el trabajo por proyecto desde la institución líder del mismo, en este caso, el Instituto de Medicina Tropical "Pedro Kourí" (IPK), fundamentalmente el documento oficial que avala la aprobación del proyecto institucional desde el IPK con las diferentes instituciones de la provincia de Sancti Spíritus.

El empleo de las técnicas a nivel empírico posibilita el estudio del sujeto y del objeto sin alterar el curso natural de su desarrollo. Se utilizaron la observación participante del contexto, entrevistas cualitativas en profundidad y basadas en conversaciones informales, encuestas a través de la aplicación de un cuestionario.

La observación participante fue utilizada en la investigación con la intensión de compartir con los miembros de la comunidad científica el contexto en que desarrollan sus investigaciones, sus experiencias del trabajo en equipo y las disímiles maneras y vías que utilizan para satisfacer sus necesidades informativas con el acceso a diferentes recursos y fuentes de información. Esta técnica en su forma más radical, consistió en observar al grupo desde dentro en su ambiente natural, donde el observador crea una interrelación con los observados que le facilita una mayor posición de cercanía psicológica aunque lo mantiene en un nivel nulo o bajo de participación. Esto significa que el investigador conversa con los miembros del grupo, trabaja con ellos, asiste a sus sesiones científicas, es decir, está presente en tantas situaciones como le sea posible. Convive con ellos, recogiendo información, detectando las 
características particulares y percibiendo las diferencias entre su mundo y el de los otros de manera tal que le permita comprender la realidad objetiva de esta comunidad científica. Con la finalidad de aprender a conocer el objeto de estudio en tantos ambientes y facetas como pueda, así como sus puntos de vistas, para aprender a usarlos, ya que como dicen Schwartz, \& Jacobs (1984), se trata de lograr una socialización secundaria, que permita no sólo saber cómo actúan los sujetos por separados, sino como logran actuar en comunidad. (SCHWARTZ, H.; JACOBS, J. (1984)

En el cuestionario se incluyeron datos cualitativos y cuantitativos de un amplio rango de encuestados; la estructura de este instrumento se presentó en dos acápites fundamentales: 1) Datos generales y 2) Comportamiento informacional; a través del primer acápite se logró obtener una caracterización general de la comunidad científica en estudio en cuanto a: formación profesional, grado de estudio, sexo, antigüedad laboral, edades, categorías científicas y/o docentes, tipo de investigación que realizaban y etapa de investigación en que se encontraban en el momento de responder al cuestionario; en el acápite número (2) comportamiento informativo, se obtuvo por resultados: los recursos y fuentes de información más utilizados por los investigadores cuando realizan sus búsquedas para satisfacer sus necesidades informativas, el uso que hacen de la información recopilada, el formato o soporte más utilizado, las últimas publicaciones realizadas, cómo efectuaban la diseminación de sus resultados científicos y el no delegar sus búsquedas informativas en profesionales de la información. El cuestionario fue previamente validado mediante su aplicación a 10 miembros de la comunidad científica, que representaron a las diferentes instituciones territoriales que eran parte del proyecto. Es importante destacar que para el diseño de este cuestionario se tomaron como antecedente otros instrumentos similares utilizados en estudios anteriores relacionados con el tema; básicamente los de Calva González, sobre comportamiento en la búsqueda de información en investigadores del área de Humanidades y Ciencias Sociales (CALVA-GONZÁLEZ, 1999); el de Guevara Villanueva que aborda el comportamiento informacional en la comunidad de matemáticos de México (GUEVARA-VILLANUEVA, 2007); la investigación de Ferrán Ferrer, sobre comportamiento informacional en la vida diaria de estudiantes de la Universidad Oberta de Cataluña (FERRÁN-FERRER, 2009) y el estudio desarrollado por Pinto Molina, Fernández Marcial y Gómez Camarero, acerca del impacto del comportamiento informacional de la calidad del servicio de las bibliotecas universitarias del área de Ciencia y Tecnología en España. (PINTO-MOLINA; FERNÁNDEZ-MARCIAL; GÓMEZ-CAMARERO, 2009)

En el análisis matemático - estadístico se utilizó el cálculo porcentual para la identificación de los recursos informativos, específicamente para determinar las fuentes documentales de la Comunidad Científica y definir el comportamiento del tema objeto de 
estudio así como el paquete estadístico SPSS 13.0 para verificar el nivel de correlación entre las variables.

La muestra para el desarrollo de esta investigación estuvo conformada por (33) investigadores que representaron a las diferentes instituciones participantes como miembros del proyecto colaborativo institucional.

El procesamiento de la información obtenida del cuestionario fue vertido en una hoja de cálculo de Microsoft Excel, codificándose y registrándose cada una de las respuestas de los participantes en la investigación, con el programa estadístico SPSS versión 13.0 para Windows, se realizó el análisis de las estadísticas descriptivas y correlaciones entre variables. (MOLINA; RODRIGO, 2010). Esta correlación se calculó utilizando tres pruebas no paramétricas: Chicuadrada $\left(\chi^{2}\right)$, Coeficiente phi de Pearson $(\varphi)$ y Coeficiente de contingencia de Cramer ( $\mathrm{V}$ de Cramer); los resultados se explicitaron a través de tablas (simples), y diferentes tipos de gráficos (barra y pastel).

\section{Resultados}

\subsection{La Comunidad Científica y sus características como grupo}

La composición de la comunidad científica que se formó a través del desarrollo de un proyecto conjunto con instituciones de la provincia de Sancti Spíritus y liderado por especialistas del Instituto de Medicina Tropical "Pedro Kourí" (IPK), en cuanto a la cantidad de profesionales, la distribución por especialidades, y el porcentaje que estos representan con respecto al grupo (Gráfico 1), se toma del documento que establece la relación institucional a través del proyecto "Condicionantes eco-biosociales de la proliferación de vectores de importancia médica y veterinaria" y que se corrobora en el cuestionario aplicado.

Gráfico 1. Formación profesional / Cantidad de profesionales

\section{Formación profesional/Cantidad de profesionales}

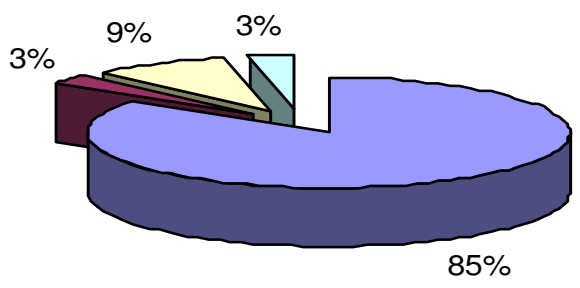

$\square$ Licenciados

$\square$ Doctor en medicina

$\square$ Ingenieros

$\square$ Técnicos

Fuente: Datos de la investigación 
Desde la composición del grupo según el sexo, se evidenció que el $45,5 \%$ de los integrantes eran féminas. Lo cual constituyó un dato significativo en cuanto al equilibrio en la estructura de la comunidad científica, pues en la mayoría de los estudios relacionados con profesiones de las ciencias naturales, puras, exactas y aplicadas existe una tendencia al predominio del sexo masculino, que en ocasiones esta suposición se ha convertido en un estereotipo. No obstante en este grupo se visualizó la oportunidad y accesibilidad de ambos sexos al desempeño dentro del proyecto, lo cual se correspondió con el hecho de que en los representantes del proyecto a nivel de instituciones, se contara con un equilibrio desde el enfoque de género.

El $51,5 \%$ de los integrantes de esta comunidad poseen título académico de Máster en Ciencias, un 6,06\% ostentan la categoría científica de Doctor en Ciencias y un 3,03\% ya ha realizado estudios postdoctorales, demostrando estas cifras que una de las razones fundamentales por las cuales surgió y se autorizó la realización de este proyecto colaborativo-institucional, fuera precisamente con el objetivo de desarrollar mayores y mejores niveles en la superación científica y académica de los profesionales del territorio en la provincia de Sancti Spíritus. Es importante señalar que el contar dentro de la comunidad con tan solo dos (2) profesionales que poseían la categoría científica de Doctor en Ciencias, constituyó un logro para el grupo que recién comenzaba su trabajo en conjunto. (Gráfico 2)

Gráfico 2. Titulación Académica de los miembros de la comunidad

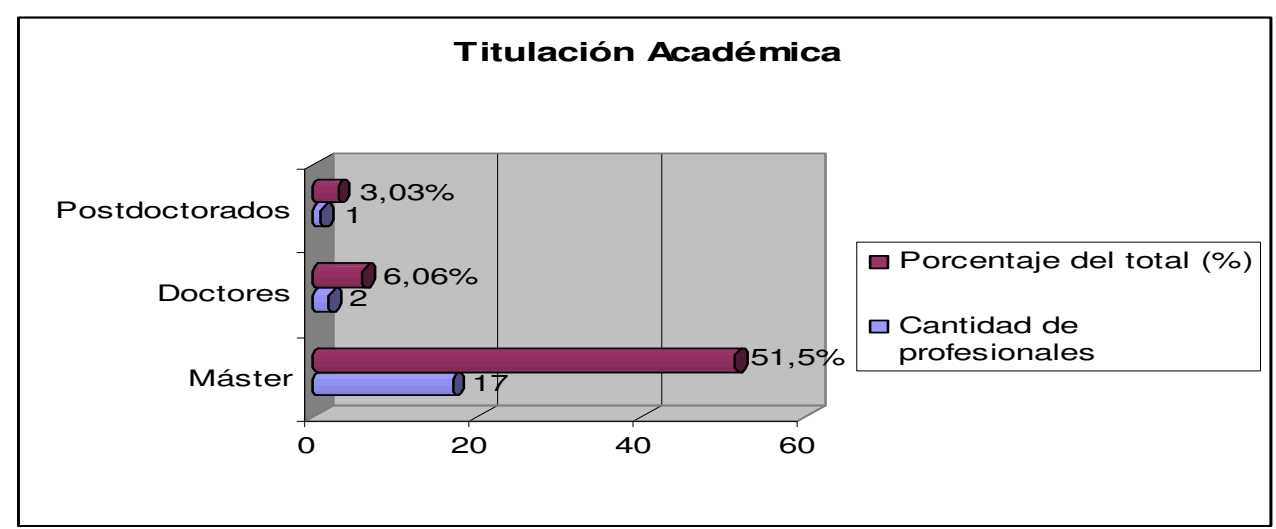

Fuente: Datos de la Investigación

Hacer referencia a una comunidad científica, indica comentar necesariamente acerca de las experiencias y características de los miembros de esta, que lo avalen como científicos. Por ello fue necesario hacer énfasis en las categorías científicas, donde se observó que tan solo 11 de los investigadores estaban categorizados, lo cual evidenció que no era un grupo con trayectoria científica fuerte y ello se correspondía entonces con la ejecución del proyecto, el cual presentaba como uno de sus principales objetivos elevar el nivel científico de los profesionales de las diferentes instituciones de la provincia Sancti Spíritus. (Gráfico 3)

Gráfico 3. Distribución por categorías científicas 


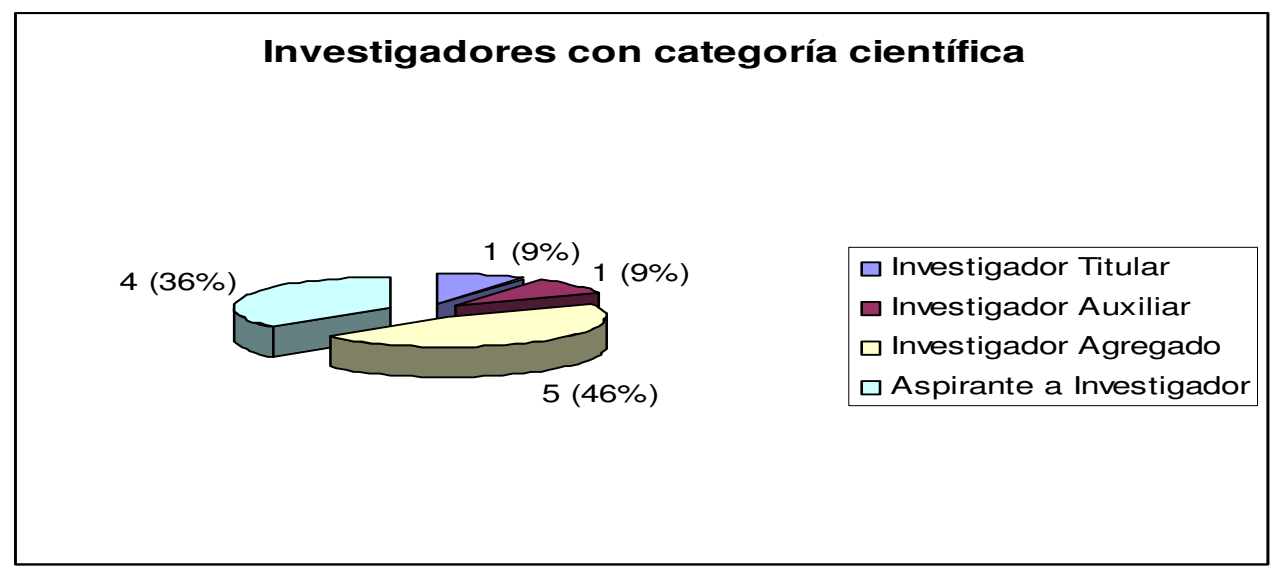

Fuente: Datos de la Investigación

En cuanto al tipo de investigación que realizaban los encuestados en el momento de aplicado el cuestionario reveló que no existe gran diferencia entre la cantidad de profesionales que trabajaban en un tipo de investigación y otra; dado que el porciento de investigadores que estaban inmersos en la realización de investigaciones de tipo aplicada era un $57,6 \%$ y los que realizaban investigaciones básicas representaban un $42,4 \%$. (Tabla 1 )

Tabla 1. Tipo de investigación que realizan los investigadores

\begin{tabular}{|c|c|c|}
\hline Tipo de investigación & $\begin{array}{c}\text { Cantidad de } \\
\text { profesionales }\end{array}$ & $\begin{array}{c}\text { Porcentaje del total } \\
(\mathbf{\%})\end{array}$ \\
\hline Básica & 14 & 42,4 \\
\hline Aplicada & 19 & 57,6 \\
\hline
\end{tabular}

Fuente: Datos de la Investigación

\subsection{Comportamiento Informacional}

\subsubsection{Análisis de los recursos y fuentes de información}

Al analizar la distribución de los recursos de información según el orden de importancia concedido por los investigadores que integran la comunidad científica estudiada, se obtuvo por resultado que fue el recurso informativo (biblioteca, hemeroteca, centro de documentación), el que alcanzó lugar prioritario en los miembros de esta comunidad científica, cuando precisan satisfacer sus necesidades informativas. (Gráfico 4)

Otro recurso de información importante que fue utilizado por ellos cuando precisaron satisfacer sus necesidades informativas lo constituyó el contacto con colegas, razón por la cual le otorgaron el segundo lugar en orden de importancia con 14 respuestas que representaron el $42,4 \%$ del total. (Gráfico 4)

El tercer lugar en la escala de importancia lo ocupó el recurso informativo Internet con una puntuación de 21 (veintiuno) respuestas para un 63,6\%, correspondiéndose con el incremento del uso de las Tecnologías de la Información y el Conocimiento (TIC) en todas las instituciones participantes en el proyecto. (Gráfico 4) 
Ocuparon el cuarto y quinto lugar en orden de importancia los recursos de información: expertos en el área, con una puntuación de 12 (doce) respuestas y el rubro colección documental propia, con 8 (ocho) respuestas respectivamente. (Gráfico 4)

Gráfico 4: Distribución de los Recursos Informativos según orden de importancia concedido por los investigadores

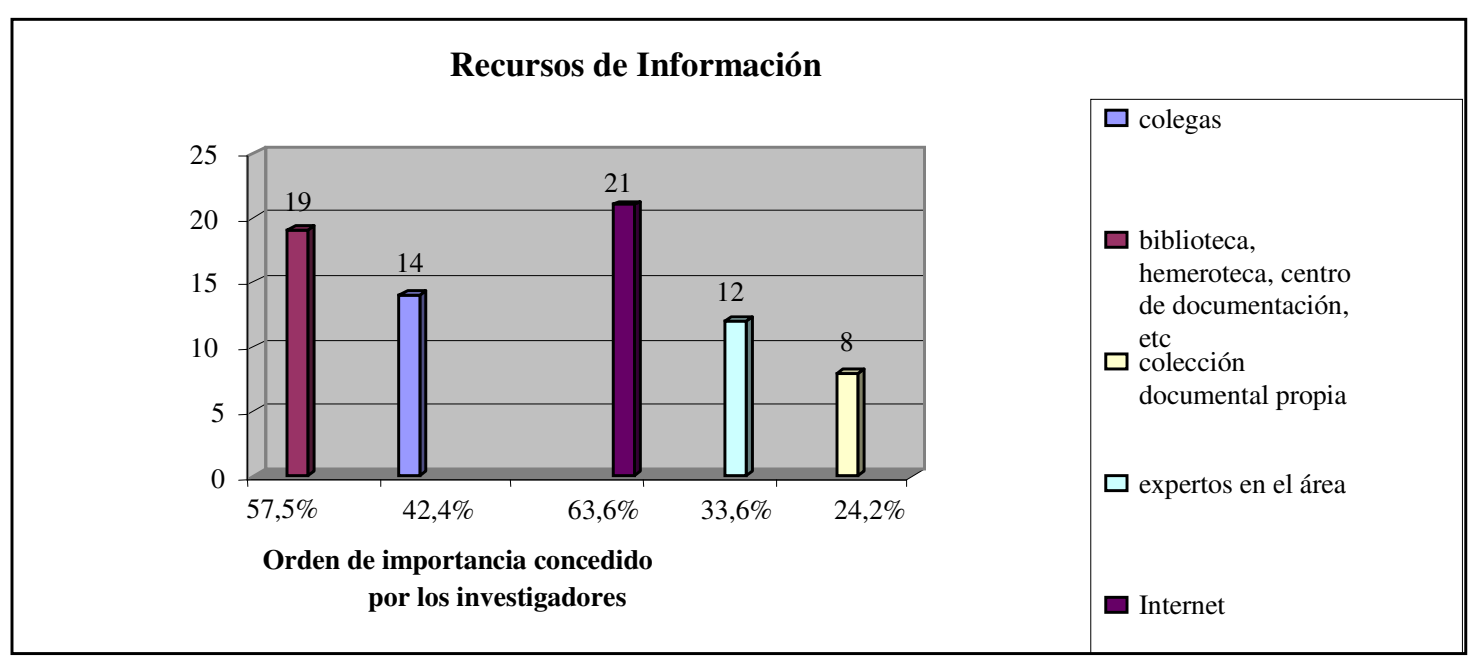

Fuente: Datos de la Investigación

De los investigadores participantes en el estudio, la mayoría de ellos seleccionaron a las publicaciones periódicas como las fuentes informativas más utilizadas para desarrollar sus acciones de investigación dentro del proyecto; tal aseveración fue corroborada con los resultados obtenidos pues precisamente este rubro ocupó el primer y segundo lugar según el orden de importancia concedido por los investigadores. (Tabla 2)

El tercer lugar según el orden de importancia concedida por los investigadores correspondió a las monografías (libros, tesis, etc), la cual resultó ser la fuente informativa que se utilizó con cierto grado de frecuencia. Es importante comentar que aunque la generalidad de los profesionales que formaron la comunidad científica provenía de las llamadas ciencias naturales, puras, exactas y aplicadas, la consulta y revisión de estas fuentes resultó imprescindibles para el avance en sus investigaciones (Tabla $\mathbf{2}$ ).

La totalidad de los miembros de la comunidad científica expresaron que usarían la información obtenida de las fuentes informativas para investigar, esto demostró el alto nivel de identificación que sienten los investigadores con el proyecto donde están insertados, cuyo objetivo principal es el desarrollo de las investigaciones del territorio.

Tabla 2. Orden de importancia concedido por los investigadores a las fuentes informativas

\begin{tabular}{|l|c|c|c|c|c|c|c|c|c|}
\hline \multirow{2}{*}{ Fuentes Informativas } & \multicolumn{7}{|c|}{ Orden según la importancia concedida por el investigador } \\
\cline { 2 - 11 } & $\mathbf{1}$ & $\mathbf{2}$ & $\mathbf{3}$ & $\mathbf{4}$ & $\mathbf{5}$ & $\mathbf{6}$ & $\mathbf{7}$ & $\mathbf{8}$ & $\mathbf{9}$ \\
\hline 1. monografías (libros, tesis, etc.) & 3 & 8 & $\mathbf{1 9}$ & 7 & 0 & 0 & 0 & 0 & 0 \\
\hline $\begin{array}{l}\text { 2. publicaciones periódicas (revistas, } \\
\text { anuarios, etc.) }\end{array}$ & $\mathbf{2 1}$ & $\mathbf{1 2}$ & 0 & 0 & 0 & 0 & 0 & 0 & 0 \\
\hline
\end{tabular}




\begin{tabular}{|l|c|c|c|c|c|c|c|c|c|}
\hline $\begin{array}{l}\text { 3. publicaciones oficiales (informes } \\
\text { de organismos nacionales e } \\
\text { internacionales) }\end{array}$ & 1 & 2 & 6 & $\mathbf{1 5}$ & 6 & 2 & 0 & 0 & 0 \\
\hline $\begin{array}{l}\text { 4. obras de consulta (diccionarios, } \\
\text { enciclopedias, directorios, etc.) }\end{array}$ & 0 & 0 & 2 & 6 & $\mathbf{1 8}$ & 4 & 2 & 0 & 0 \\
\hline $\begin{array}{l}\text { 5. fuentes referenciales (índices, } \\
\text { abstracts, bibliografías) }\end{array}$ & 6 & 11 & 10 & 3 & 1 & 0 & 0 & 0 & 0 \\
\hline $\begin{array}{l}\text { 6. materiales audiovisuales (videos, } \\
\text { casetts, etc.) }\end{array}$ & 0 & 0 & 1 & 1 & 7 & 14 & 7 & 4 & 0 \\
\hline $\begin{array}{l}\text { 7. documentos técnicos (patentes, } \\
\text { planos, mapas, etc.) }\end{array}$ & 0 & 0 & 0 & 1 & 0 & 9 & $\mathbf{1 9}$ & 4 & 0 \\
\hline $\begin{array}{l}\text { 8. fuentes de datos numéricos } \\
\text { (indicadores, estadísticas, etc }\end{array}$ & 0 & 0 & 0 & 0 & 1 & 2 & 5 & $\mathbf{2 4}$ & 0 \\
\hline 9. otra (especifique) & 0 & 0 & 0 & 0 & 0 & 0 & 0 & 0 & 10 \\
\hline
\end{tabular}

Fuente: Datos de la Investigación

Entre los formatos o soportes informativos más utilizados en la búsqueda y recuperación de la información fueron identificados, el texto electrónico con un $54,5 \%$ y el texto impreso con un $45,5 \%$, se observó la existencia de cierto equilibrio en cuanto a la utilización de ambos soportes informativos. (Tabla 3). En este apartado se hizo necesario señalar que actualmente existe una tendencia al aumento en cuanto a la disponibilidad de los recursos electrónicos, fundamentalmente las revistas electrónicas las cuales presentan gran aceptación en la comunidad científica que se estudió; esto presupone un cambio gradual en el uso de los documentos impresos a documentos electrónicos. (PINTO-MOLINA; FERNÁNDEZRAMOS, 2010)

Tabla 3. Formatos/soportes más utilizados por los investigadores

\begin{tabular}{|l|c|c|}
\hline Formatos & Cantidad de profesionales & Por ciento \\
\hline Impreso & 15 & 45,5 \\
\hline Texto electrónico & 18 & 54,5 \\
\hline
\end{tabular}

Fuente: Datos de la Investigación

\subsubsection{Publicaciones y resultados científicos}

Se tuvieron en cuenta para recopilar información acerca del Comportamiento Informacional (CI) de los miembros de la comunidad científica que se investiga, otros rubros como:

últimas publicaciones realizadas: Se constató que el 90,9\% de los investigadores realizaron sus últimas publicaciones en un tiempo inferior a cinco (5) años, un 9,09\% las realizó entre los últimos 5 y 10 años, lo que auguraba desde ese momento un buen comienzo para el posterior desempeño del grupo; donde sus miembros estaban conscientes de la necesidad de publicar constantemente como una vía para dar a conocer el progreso de sus investigaciones, el contacto con sus pares y la actualización de sus conocimientos.

Diseminación de los resultados científicos: Resultó baja la cantidad de investigadores que respondieron comunicar sus resultados científicos antes de ser publicados; los mismos expresaron que de las diferentes formas o vías para diseminar sus resultados la más utilizada por ellos es a través de su participación en eventos científicos, se revela así el contacto 
interpersonal y la comunicación cara a cara como la forma más efectiva de actualización informativa.(Gráfico 5)

Gráfico 5: Diseminación de los resultados de los miembros de la comunidad científica

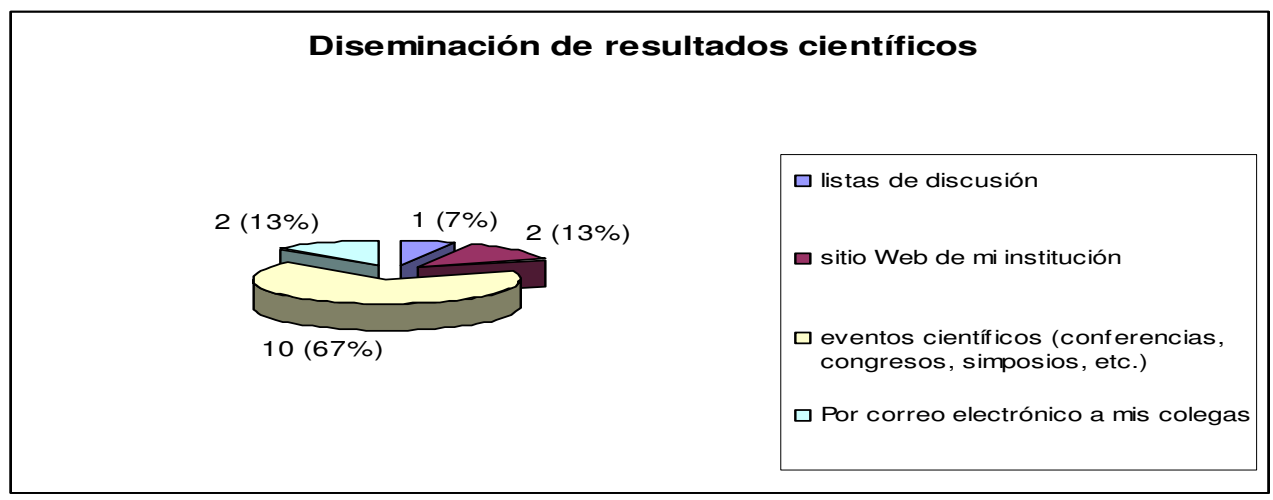

Fuente: Datos de la Investigación

Delegan sus búsquedas de información en otras personas: El 93,9\% de los investigadores de esta comunidad científica respondieron que nunca delegan en otra persona su búsqueda de información, esto demostró lo consultado en la literatura, cómo los profesionales pertenecientes a las ciencias naturales, puras, exactas y aplicadas preferían realizar sus propias búsquedas sin tener necesidad de solicitar o depender de otras personas (GUEVARA VILLANUEVA, 2007); sin embargo este comportamiento informativo en los miembros del grupo denotó que a pesar de ser una comunidad de nueva formación, la misma tenía como líderes a especialistas altamente calificados y con vasta experiencia en la búsqueda, acceso y uso de la información; conocimientos estos que se transmitieron a los más jóvenes dentro del grupo.

\subsection{Análisis de la relación y/o asociación entre variables}

Para el análisis descriptivo y estadístico del cruce de variables se realizaron las pruebas no paramétricas Chi-cuadrada $\left(\chi^{2}\right)$, el Coeficiente phi $(\varphi)$ de Pearson y el Coeficiente de contingencia de Cramer (V), donde la hipótesis nula a contrastar sería la de independencia entre las variables, siendo la hipótesis alternativa la de dependencia entre ellas. Las escalas de asociación o correlación que se tuvieron en consideración para demostrar la independencia o dependencia de las variables relacionadas, fueron las siguientes:

Para prueba Chi-cuadrada $\left(\chi^{2}\right)$

$\hat{\chi}^{2}>\chi^{2}(1-\alpha, g l) \Rightarrow$ Se rechaza la hipótesis nula (dependencia entre las variables) con $1-\alpha$ de confiabilidad y $g$ l grados de libertad. El nivel de confianza utilizado fue del $95 \%$, es decir, $\alpha=0.05$.

$\hat{\chi}^{2}<\chi^{2}(1-\alpha, g l) \Rightarrow$ Se acepta la hipótesis nula (independencia entre las variables) con $1-\alpha$ de confiabilidad.

Coeficiente phi de Pearson $(\varphi)$ 
Normas interpretativas sugeridas por Cohen a la hora de evaluar la intensidad de la asociación (tamaño del efecto) para este coeficiente: $\varphi \leq 0.3 \Rightarrow$ nivel bajo de asociación; $0.3<\varphi \leq 0.5 \Rightarrow$ nivel medio de asociación; $\varphi>0.5 \Rightarrow$ nivel alto de asociación.

\section{Coeficiente de contingencia ( $V$ ) de Cramer}

El coeficiente $V$ de Cramer oscila entre 0 (independencia) y 1 (dependencia), de modo que cuanto más próximos a 1 sean los valores, ello indicará mayor intensidad en la asociación de las variables.

La relación que existe entre el "grado de estudio de los investigadores" y su sistematicidad a utilizar en primer orden las publicaciones periódicas, se halló que de 17 investigadores que plantearon acudir en primer lugar al uso de las publicaciones periódicas, 14 tenían realizados estudios de maestría lo que representa un 85,7\%. Los investigadores que tenían titulación académica de Doctor en Ciencias y estudios posdoctorales expusieron que las publicaciones periódicas constituían una fuente informativa fundamental para la realización de sus investigaciones. Al calcularse las medidas de asociación se obtuvo: $\hat{\chi}^{2}=0.486$ (independencia entre las variables), $\varphi=0.169$ y $\mathrm{V}=$ 0.169 , por lo tanto sobre la base de esos resultados y teniendo en cuenta las escalas de valoración de los coeficientes de Pearson y Cramer, se determinó que entre las variables "Investigadores que acuden al uso de las publicaciones periódicas en primer orden" y "Grado de estudio", no existe una relación directa, porque independientemente del nivel de estudios que presenten los investigadores, utilizarán como fuente informativa principal las publicaciones periódicas con el objetivo de continuar desarrollando sus actividades investigativas.

Al analizar la relación que existe entre las variables "Edad de los investigadores" e "Investigadores que acuden en primer orden al uso de las publicaciones periódicas", los resultados revelaron que los investigadores utilizaron las publicaciones periódicas en un por ciento elevado y que la edad no influyó en la preferencia por su uso, eso sí, fueron los investigadores cuyas edades están incluidas en el rango de 55 a 64 años, los de 35 a 44 años y los de 45 a 54 años, los que manifestaron hacer un uso preferencial por esta fuente informativa (publicaciones periódicas). Al calcular las medidas de asociación so obtuvo por resultado: $\hat{\chi}^{2}=3.714$ (independencia entre las variables), $0.3<\varphi \leq 0.5$ presentó un nivel medio de asociación y $\mathrm{V}=0.335$, se determinó entonces que las variables eran independientes, por lo que se infiere que la "Edad de los investigadores" resultó ser una variable poco significativa que demostrara el porqué los miembros de la comunidad científica utilizaban en primer orden la publicaciones periódicas.

Los investigadores que dijeron consultar las publicaciones periódicas en primer orden según sus etapas de investigación sumaron 7 sujetos que se encontraban en la etapa inicial de su investigación, de ellos 4 confirmaron hacer uso de las publicaciones periódicas en primer orden lo que representa un $57,1 \%$; en la fase intermedia se encontraban 23 
investigadores, de ellos 15 manifestaron utilizar las publicaciones periódicas como la fuente informativa de prioridad esto representa un $65,2 \%$ y en la etapa final 2 investigadores de 3 expusieron que ellos también hacían uso de las publicaciones periódicas en primer lugar (Tabla 4); cuando se calcularon las medidas de asociación se obtuvieron que: $\hat{\chi}^{2}=0.164$ (independencia entre las variables), $\varphi=0.071$ (era menor a 0.3 ) y $\mathrm{V}=0.071$ (más cerca a 0 que a 1 ), determinándose que estas variables son independientes; esto se debe a que los investigadores utilizan las publicaciones periódicas indistintamente de la etapa de investigación en que se encuentren.

Tabla 4. Relación Etapa de investigación /Investigadores que recurren en 1er orden al uso de publicaciones periódicas

\begin{tabular}{|c|c|c|c|}
\hline \multicolumn{4}{|c|}{$\begin{array}{c}\text { Relación Etapa de investigación/Investigadores que recurren en primer orden al uso de publicaciones } \\
\text { periódicas }\end{array}$} \\
\hline Etapa de investigación & $\begin{array}{c}\text { Cantidad de } \\
\text { investigadores }\end{array}$ & $\begin{array}{l}\text { Investigadores que recurren en primer } \\
\text { lugar al uso de las publicaciones periódicas }\end{array}$ & $\%$ \\
\hline Inicial & 7 & 4 & 57,1 \\
\hline Intermedia & 23 & 15 & 65,2 \\
\hline Final & 3 & 2 & 66,6 \\
\hline
\end{tabular}

Fuente: Datos de la Investigación

En el análisis de la relación que existía entre el grado de estudios y el acudir a la biblioteca como recurso principal para el desarrollo de las actividades científico-investigativas de los miembros de la comunidad, los resultados obtenidos durante la ejecución del estudio demostraron que 13 investigadores con titulación académica de Máster, los 2 Doctores en Ciencias y el único investigador que había realizado estudios posdoctorales, reafirmaron que la biblioteca es el recurso de información por excelencia más utilizado por ellos. Al desarrollar las fórmulas se obtuvo por resultado que el estadígrafo $\hat{\chi}^{2}=0.228$ (independencia entre las variables), $\varphi=0.116$ (era menor a 0.3 ) y $\mathrm{V}=0.116$ (más próximo a 0 que a 1), dicho resultado corroboró la no existencia de relaciones directas entre las variables "Grado de estudio" e"Investigadores que recurren en primer orden a las bibliotecas", por considerarse la biblioteca como un espacio obligatorio para el avance en las actividades científicas de la comunidad investigada.

La existencia de asociación entre las variables edad de los investigadores y la asistencia de estos a la biblioteca como primer lugar donde buscaban información, los resultados obtenidos fueron los siguientes: 2 de 9 investigadores cuyas edades oscilaban entre 25-34 años $(22 \%)$, respondieron que era la biblioteca el recurso informativo por excelencia al cual recurrían en primer orden para realizar sus búsquedas de información; 4 de 7 sujetos $(57,1 \%)$, expresaron que la biblioteca era su recurso de información principal; de 14 investigadores, 10 de ellos $(71,4 \%)$ reconocieron a la biblioteca como un recurso de información importante para el avance de sus actividades científicas; por último los sujetos cuyo rango etéreo oscilaba entre 55 a 64 años expusieron en un $100 \%$ su predilección por el uso de la biblioteca en primer lugar (Tabla 
5). Al calcular las relaciones de asociación se obtuvo por resultado que el valor de $\hat{\chi}^{2}=7.916$ (dependencia entre las variables), $\varphi=0.490$ (cumple con la condición $0.3<\varphi \leq 0.5$ por) y $V=0.490$ (está próximo a 0.5 ) las pruebas no paramétricas demostraron el nivel medio de asociación es decir la dependencia que existía entre "Edad de los Investigadores" respecto a la variable "Investigadores que recurren en primer orden a las bibliotecas. En este resultado corrobora lo planteado por Calva González (1995), Vigeannel (2002) y Flower (2004), cuando defienden firmemente su postura sobre como la biblioteca en la actualidad continua siendo el recurso informativo por excelencia que es más utilizado por los investigadores de cualquier ciencia; demostrándose en este ítem como los investigadores de edades más avanzadas han inculcado en las jóvenes generaciones la importancia de recurrir a las bibliotecas como primera opción para satisfacer sus necesidades informativas.

Tabla 5. Relación Edad de Investigadores/Investigadores que recurre en primer orden a las bibliotecas

\begin{tabular}{|l|c|c|c|}
\hline \multicolumn{2}{|c|}{ Relación Edad de Investigadores /Investigadores que recurren en primer lugar a las bibliotecas } \\
\hline Edad de Investigadores & $\begin{array}{l}\text { Cantidad de } \\
\text { investigadores }\end{array}$ & $\begin{array}{l}\text { Investigadores que recurren en primer } \\
\text { lugar al uso de las bibliotecas }\end{array}$ & $\%$ \\
\hline Menores de 25 años & - & - & 22,2 \\
\hline De 25-34 años & 9 & 2 & 57,1 \\
\hline De 35-44 años & 7 & 10 & 71,4 \\
\hline De 45-54 años & 14 & 3 & 100 \\
\hline De 55-64 años & 3 & - & \\
\hline Mayores de 64 años & - & & \\
\hline
\end{tabular}

Fuente: Datos de la Investigación

De 7 investigadores que se encontraban en la etapa inicial de sus estudios, solo 2 un 28,5\%, expusieron que acudían en primer lugar a las bibliotecas; en la fase intermedia de su investigación se encontraban 23 integrantes del grupo y de ellos 15 un 65,2\% reafirmaron a la biblioteca como el lugar principal para la realización de sus búsquedas de información en sus actividades de investigación y en la etapa final se hallaban 3 investigadores de ellos 2 un 66,6\% reconoció a la biblioteca el lugar por excelencia para la búsqueda de la información. Se calcularon las medidas de asociación $y$ se obtuvo como valor de $\hat{\chi}^{2}=3.062$ (independencia entre las variables), $\varphi=0.305$ (era mayor a 0.3) y $\mathrm{V}=0.305$ (estaba más cerca a 0 que a 1 ), por lo tanto se corroboró que: "Investigadores que acuden en primer lugar a las Bibliotecas" y "Etapa de la Investigación", son variables que no tienen ninguna relación, pues los investigadores visitan la biblioteca independientemente de la etapa de investigación en que se encuentren.

De los 14 sujetos que realizaron investigaciones de tipo básica durante el período en que se realizó el estudio, solo un $71,4 \%$ recurren a las bibliotecas en primer orden cuando precisan información; y de 19 individuos que se encontraban realizando investigación de tipo aplicada, solamente el $47,3 \%$ respondieron acudir a la biblioteca en primer lugar para buscar información (Tabla 6). Se calcularon las fórmulas de las 
medidas de asociación y/o relación y se obtuvo el valor de $\hat{\chi}^{2}=1.910$ (independencia entre las variables), $\varphi=0.241$ (era menor a 0.3 ) y $\mathrm{V}=0.241$ (con más cercanía a 0 que a 1 ) por lo que se determinó que las variables son independientes debido a que los investigadores visitarán la biblioteca independientemente del tipo de investigación que desarrollen.

Tabla 6. Relación Tipo de investigación/Investigadores que recurren en primer orden a las bibliotecas

\begin{tabular}{|c|c|c|c|}
\hline \multicolumn{2}{|c|}{ Relación Tipo de investigación /Investigadores que recurren en primer lugar a las bibliotecas } \\
\hline Tipo de investigación & $\begin{array}{c}\text { Cantidad de } \\
\text { investigadores }\end{array}$ & $\begin{array}{c}\text { Investigadores que recurren en primer } \\
\text { lugar al uso de las bibliotecas }\end{array}$ & $\%$ \\
\hline Básica & 14 & 10 & 71,4 \\
\hline Aplicada & 19 & 9 & 47,3 \\
\hline
\end{tabular}

Fuente: Datos de la Investigación

Según las variables "Edad de los investigadores" e "Investigadores que acuden en primer lugar a los colegas cuando precisan información", dio por resultado que los sujetos cuyas edades oscilan en el rango de 25 a 34 años, acudían a los colegas en primer lugar 2 sujetos para un 22,2\%; en las edades entre 35 a 44 años, solo 4 un $57,1 \%$ reconocieron que acudían a sus pares o colegas en primer lugar cuando necesitaban información, siendo el mismo porcentaje para los sujetos cuyas edades estaban comprendidas en el rango de 45 a 54 años; por último los investigadores con edades comprendidas entre 55 a 64 años dijeron acudir a sus colegas en primer orden (Tabla 7). Al desarrollar las fórmulas de asociación y/o relación entre las variables "Investigadores que acuden en primer lugar a los colegas cuando necesitan de información" y "Edad de los investigadores", se obtuvo el valor de $\hat{\chi}^{2}=3.513$ (independencia entre las variables), $\varphi=0.326$ (con un nivel medio bajo de asociación) y $\mathrm{V}=0.326$ (más próximo a 0 que a 1 ), se confirmó la existencia de independencia entre las variables en estudio, lo que infirió que el contacto o no con sus pares o colegas se desarrolla independientemente de la edad de los investigadores, es decir, hoy día la tendencia para elevar el desarrollo científico en cualquier contexto presenta su basamento fundamental en el contacto con colegas o pares; basamento que desde la conformación misma de esta comunidad científica se ha desarrollado; demostrándose de esta forma que sean muy jóvenes o no siempre se contactará con los pares o colegas para mantenerse actualizados en los avances y resultados científicos que se presenten en sus áreas del conocimiento.

Tabla 7. Relación Edad Investigadores/Investigadores que recurre en primer orden a los colegas 


\begin{tabular}{|c|c|c|c|}
\hline \multicolumn{4}{|c|}{ Relación Edad Investigadores /Investigadores que recurren en primer lugar a los colegas } \\
\hline Edad Investigadores & $\begin{array}{c}\text { Cantidad de } \\
\text { investigadores }\end{array}$ & $\begin{array}{c}\text { Investigadores que recurren en } \\
\text { primer lugar a los colegas }\end{array}$ & $\%$ \\
\hline Menores de 25 años & - & - & 22,2 \\
\hline De 25 a 34 años & 9 & 2 & 57,1 \\
\hline De 35 a 44 años & 7 & 8 & 57,1 \\
\hline De 45 a 54 años & 14 & 2 & 66,6 \\
\hline De 55 a 64 años & 3 & - & \\
\hline Más de 64 años & - & & \\
\hline
\end{tabular}

Fuente: Datos de la Investigación

Las variables "Investigadores que acuden en primer orden a los colegas" y "Etapas de investigación" en que se encuentran los miembros de la comunidad científica estudiada, demostró que en cada una de las etapas de investigación era alto el por ciento de investigadores que recurría en primer lugar a los colegas o pares cuando necesitaban información (Tabla 8). Al calcularse las fórmulas de medidas de asociación y/o relación entre las variables "Investigadores que acuden en primer lugar a los colegas" y "Etapa de Investigación", se obtuvo el valor de $\hat{\chi}^{2}=1.982$ (independencia entre las variables), $\varphi=0.245$ (era menor a 0.3 ) y $V=0.245$ (estaba más cerca a 0 que a 1 ), se demuestra que las variables eran independientes y que en cualquier etapa durante el proceso de investigación en que se encontraban los miembros de esta comunidad científica, contactarían con sus colegas o pares de manera prioritaria de ser necesario para el desarrollo de la investigación que estaban realizando.

Tabla 8. Relación Etapas de Investigación/Investigadores que recurren en primer orden a los colegas

\begin{tabular}{|c|c|c|c|}
\hline \multicolumn{3}{|c|}{ Relación Etapas de Investigación /Investigadores que recurren en primer lugar a los colegas } \\
\hline Etapas de Investigación & $\begin{array}{c}\text { Cantidad de } \\
\text { investigadores }\end{array}$ & $\begin{array}{c}\text { Investigadores que recurren en primer } \\
\text { lugar a los colegas }\end{array}$ & $\%$ \\
\hline Inicial & 7 & 5 & 71,4 \\
\hline Intermedia & 23 & 10 & 43,8 \\
\hline Final & 3 & 1 & 33,3 \\
\hline
\end{tabular}

Fuente: Datos de la Investigación

Los investigadores que afirmaron recurrir a sus colegas o pares en primer lugar cuando precisan de información, según el tipo de investigación que realizaban en el momento en que fueron encuestados se correspondió con la siguiente distribución: de 14 sujetos que realizaron investigaciones de tipo básica, solo un 35,7\%, expresaron acudir en primer lugar a sus colegas o pares; mientras que a las investigaciones de tipo aplicada se dedicaban 19 investigadores y de ellos un $57,9 \%$ alegaron contactar con sus colegas o pares en primera opción cuando necesitaban de información. Al calcular la asociación y/o relación de ambas variables se obtuvo por resultado que el valor de $\hat{\chi}^{2}=1.588$ (independencia entre las variables), $\varphi=0.219$ (era menor a 0.3 ) y $V=0.219$ (estuvo más cerca a 0 que a 1), determinándose que las variables "Investigadores que acudían 
en primer lugar a los colegas cuando necesitaban información" y "Tipo de Investigación", no presentaban ninguna relación y/o asociación, por lo que estas variables resultaron ser totalmente independientes, demostrándose de esta manera que los investigadores contactarían a sus colegas o pares estuvieran en un tipo u otro de investigación, es decir el participar en una investigación básica o aplicada no interfiere en lo absoluto que los integrantes de la comunidad científica contacten a sus pares en cualquier momento que precisaran consultarlos.

\section{Discusión}

En este acápite se discuten los resultados obtenidos con la aplicación de los diferentes métodos y técnicas de investigación empleados para la recogida de información, así como se enfatiza en las principales argumentaciones que han emanado de la investigación, donde algunos autores coinciden en afirmar que los investigadores de las ciencias puras, naturales, exactas y aplicadas, presentan las mismas características en la forma en que buscan, recuperan y utilizan la información; por lo tanto para la realización de esta discusión se toma como punto de partida tal aseveración; debido a que la comunidad científica en estudio, está constituida por profesionales cuyas especialidades responden precisamente a estas ciencias (naturales, puras, exactas y aplicadas).

Respecto al uso de la información dentro de las comunidades que responden a uno de estos tipos de ciencias, la literatura revisada durante el estudio, señala que los investigadores de estas áreas, en sentido general utilizan información relevante, precisa y oportuna; la cual adquieren por medio de las revistas, anuarios, etc., afirmándose así que las publicaciones periódicas constituyen la fuente de información con mayor uso por parte de los investigadores en estas comunidades científicas (HERNÁNDEZ-SALAZAR, 2001; PINTO-MOLINA; FERNÁNDEZMARCIAL; GÓMEZ-CAMARERO, 2009). Con el uso creciente de la información electrónica se hace particularmente evidente un tipo específico de fuente de información, las revistas electrónicas, las cuales según las investigaciones realizadas se han convertido en uno de los formatos más populares utilizados entre los investigadores de las diferentes áreas. (PINTO-MOLINA; FERNÁNDEZ-MARCIAL; GÓMEZCAMARERO, 2009). Otro elemento que caracteriza a comunidades de investigadores del área de las ciencias (puras, naturales, exactas y aplicadas) según la literatura, consiste en plantear que los investigadores de dicha área delegan sus búsquedas de información en otras personas o en profesionales de la información. (SÁNZ-CASADO, 1994). Se argumenta además que el contacto con colegas resulta ser el recurso de información primordial; quiere esto decir, que la comunicación entre pares se convierte en el medio más importante para los investigadores de estas 
comunidades cuando precisan de información. (KIRSCH, 1979; SÁNZ, 1994; FLOWER, 2004 citado por GUEVARA-VILLANUEVA, 2007).

La utilización de las bibliotecas desempeña un rol fundamental en el progreso de las actividades científicas de los investigadores de estas ciencias, pues resulta ser la biblioteca el lugar de obligada visita por parte de los investigadores porque es allí donde se preparan e instruyen para continuar desarrollando sus trabajos científicos; son los autores Calva (1995), Vigeannel (2002) y Flowler (2004), quienes defienden esta postura de manera firme cuando afirman que la biblioteca continua siendo el recurso informativo por excelencia más usado por los investigadores de cualquier ciencia. (CALVA-GONZÁLEZ, 1995; VIGEANNEL, 2002; FLOWLER, 2004 citado por GUEVARA-VILLANUEVA, 2007). Por otro lado French (1990) defiende la posición de que el recurso principalmente utilizado por los científicos dedicados a estas ciencias es precisamente el contacto con otros colegas, con lo cual queda de manifiesto que este comportamiento informativo se inscribe en la dinámica de los colegios invisibles que existen en las áreas científicas. (FRENCH-BEBERLEE, 1990 citado por CALVA-GONZÁLEZ, 2004).

Partiendo entonces de las generalizaciones realizadas por los autores antes mencionados, acerca de los patrones del Comportamiento Informacional (CI) que manifiestan los investigadores de las comunidades científicas del área de las ciencias (puras, naturales, exactas y aplicadas); se decide realizar esta disertación sobre la base de las generalizaciones antes expuestas, que para la comunidad científica que se investigó quizás resulte similar.

Los resultados obtenidos de la aplicación del cuestionario a los miembros de la comunidad científica formada a partir de un proyecto colaborativo institucional demostraron que:

I La biblioteca continua siendo el recurso de información más utilizado por los investigadores de la comunidad científica investigada, coincide este resultado con lo planteado por Calva González (1995), Vigeannel (2002) y Flowler (2004), cuando afirmaban que el recurso prioritario para cualquier investigador siempre sería la biblioteca. Sin embargo es importante señalar que el ítem contacto con colegas o pares ocupó el segundo lugar en cuanto a orden de importancia según los investigadores, este resultado se acerca a por lo planteado por French (1990), cuando defiende su postura al afirmar que es el contacto con los colegas el recurso de información más importante para las comunidades científicas dedicadas al desarrollo de las llamadas ciencias puras, naturales y exactas; concluyendo entonces que el contacto con pares o colegas es también un recurso de información significativo para los miembros de esta comunidad científica. 
II En cuanto a las fuentes informativas se confirma lo expresado por Hernández Salazar (2001), cuando afirma que son las publicaciones periódicas (revistas, anuarios, etc), las más utilizadas por los investigadores pertenecientes al área de las ciencias naturales, puras, exactas y aplicadas, afirmación esta que coincide con los resultados obtenidos durante la investigación en la comunidad científica formada a partir de un proyecto colaborativo, donde sus miembros proceden de las diferentes áreas de las ciencias (naturales, puras, exactas y aplicadas). Igual similitud presenta este resultado con lo expresado por Pinto Molina et al (2009), cuando expone que las revistas en formato electrónico han tenido una excelente acogida por parte de los investigadores de esta comunidad, y quienes consideran que las revistas científicas en soporte electrónico constituye un canal muy importante de comunicación para cualquier investigador; esto lo expresan a través de múltiples razones como: la facilidad de acceso a la información, la calidad de los contenidos, el aumento creciente de su uso en el ámbito científico, etc. (PINTO-MOLINA; FERNÁNDEZ-MARCIAL; GÓMEZ-CAMARERO, 2009)

III Las tecnologías de la información, han provocado que el texto electrónico ocupe un lugar cada vez más importante para esta comunidad científica, ejemplo de ello es el tercer lugar que conquista Internet según el orden de importancia que declararon los investigadores al responder el cuestionario aplicado; no obstante esto no significa que el soporte impreso no se use, solo que con la introducción de las tecnologías, el acceso a la literatura especializada es más rápido, debido a la disponibilidad que las revistas, monografías, obras de consulta, bases de datos y otras presentan en la red, sin importar la distancia o el lugar donde sean producidas. La utilización que los investigadores de la comunidad científica hacen de Internet puede catalogarse de favorable ya que ha influido positivamente en el avance en sus actividades científicas. A pesar del incremento del uso de las tecnologías de la información, el formato impreso aún mantiene alta aceptación en los integrantes de la comunidad, pues como bien planteara Vigeannel (2002), aún permanece la inclinación por el documento impreso y no terminan de inclinarse preferencialmente por el documento electrónico; aunque las cifras reflejan que la tendencia actual está dirigida hacia el texto electrónico, pero aún no deja de lado el texto impreso; se manifiesta de esta manera la existencia de cierta resistencia al cambio dentro de la propia comunidad estudiada. En este apartado las autoras del presente informe 
concuerdan con lo planteado por Ziming (2008), cuando expresa que los usuarios desean un entorno de información híbrido donde la información en línea no sustituya la información en formato impreso, y de esta forma los usuarios tengan nuevas oportunidades de elegir cuál de ellas utilizar. (ZIMING, 2008 citado por PINTO-MOLINA; FERNÁNDEZRAMOS, 2010)

\section{Conclusiones}

Los patrones de Comportamiento Informacional (CI) de los investigadores que conforman la comunidad científica estudiada presentan coincidencias o puntos de contacto, respecto a investigaciones similares realizadas en otros países y consultadas para este estudio, destacándose la biblioteca como el recurso de información más utilizado, el uso de las publicaciones periódicas y el contacto con colegas o pares como opción prioritaria para acceder a los resultados publicados de primera mano. Existe una progresiva tendencia a un mayor uso del texto electrónico debido al creciente acceso a las tecnologías de información, pero sin desechar el uso del texto impreso. Los investigadores de la comunidad científica no delegan la actividad de búsqueda informativa en otras personas o profesionales de la información aunque sí acuden a estos últimos cuando presentan dificultades con las estrategias de búsqueda.

\section{Referencias}

BATES, M. J. Information Behaviour. In: Encyclopedie of Library and Information Sciences. New York: CRC Press, 2010.

BELKIN, N. J. Anomalous status of Knowledge as a Basis for information retrieval. Canadian Journal Information Science. Canadian,p.133-143, 1980.

CALVA-GONZÁLEZ, J. J. La investigación sobre necesidades de información en comunidades de usuarios. Investigación Bibliotecológica. México, v.18, n. 37, p. 24-55, 2004.

FERRÁN FERRER, N. Towards a personalised virtual library: indications from navigational and personal information behaviour of e-learning students. Disertación (Tesis en opción al título de Doctor en Ciencias). Departamento de Biblioteconomía y Documentación, Universidad de Barcelona, Barcelona, 2009.

FISHER, K. E.; ERDELEZ, S.; MCKECHNIE, L. E. Theories of information behavior. Medford, N.J: Information Today, 2005. Disponible en: http://informationr.net/ir/reviews/revs217.html. Consultado el: 22 set. 2010.

FOSTER, A. A non-linear model of information seeking behaviour. Information Research, 2005. Disponible en: http://informationr.net/ir/10-2/paper222.html. Consultado el: 02 ago. 2009. 
GONZÁLEZ-TERUEL, A. La perspectiva del usuario y del sistema en el estudio del comportamiento informacional. Teoría de la Educación: Educación y Cultura en la Sociedad de la Información. España, v. 12, n. 1, p. 28-46, 2010.

GONZÁLEZ-TERUEL, A.; ABAD-GARCÍA, M. F. Information needs and uses: an analysis of the literature published in Spain, 1990-2004. Library \& Information Science Research. España, v. 29, n. 1, p. 30-46, 2007.

GUEVARA-VILLANUEVA, A. La comunidad de matemáticos en México: su comportamiento en la búsqueda de información. Anales de la Documentación, España, n. 10, p. 163-184, 2007.

HERNÁNDEZ-SALAZAR, P. Análisis de los modelos de comportamiento en la búsqueda de información. Ciencia de la Información. Brasilia, v. 36, n. 1, p. 136-146, 2007.

MOLINA, G.; RODRIGO, M.F. Estadísticos de asociación entre variables. España: Universidad de Valencia. Disponible en: http://ocw.uv.es/ciencias-de-lasalud/pruebas-1/1-3/t_08-1.pdf. Consultado el: 14 ene. 2011.

PINTO-MOLINA, M; FERNÁNDEZ-RAMOS, A. Spanish Faculty Preferences and Usage of Library Services in the Field of Science and Technology. portal: Libraries and the Academy, v. 10, n. 2, p. 215-239, 2010.

PINTO-MOLINA, M.; FERNÁNDEZ-MARCIAL, V.; GÓMEZ-CAMARERO, C. The Impact of Information Behavior in Academic Library Service Quality: A Case Study of the Science and Technology Area in Spain. The Journal of Academic Librarianship. doi:10.1016/j.acalib.2009.11.008.

SANZ CASADO, E. Manual de estudios de usuarios. Madrid: Fundación Germán Sánchez Ruipérez, 1994.

WILSON, T. D. A re-examination of information seeking behaviour in the context of activity theory. Information Research, v. 11, n. 4, 2006. Disponible en: http://InformationR.net/ir/11-4/paper260.html. Consultado el: 18 mar.2010 WILSON, T. D. Human information behaviour. Informing Science, v. 3, n. 1 , p. 49-55, 2006.

WILSON, T. D. Models in information behaviour research. Journal of Documentation, v. 55, n. 3, p. 249-270, 1999.

WILSON, T. D. Information needs and uses: 50 years of progress? In: VICKERY, B. C. (Ed.). Fifty years of information progress: a Journal of Documentation Review. London: Aslib, 1994. p. 15-51.

WILSON, T. D. On user studies and information needs. Journal of Documentation, v. 37, n. 1, p. 3-15, 1981.

WILSON, T.D.; WALSH, C. Information behaviour: an interdisciplinary perspective. Sheffield: University of Sheffield, Department of Information Studies, 1996.

ZIMING, L. Paper to Digital: documents in the information Age. ABC-CLIO, 2008. 